\title{
PRÁTICAS DE GESTÃO DO CONHECIMENTO NAS ATIVIDADES DE ORGANIZAÇÃO DE ENSINO NA EDUCAÇÃO PROFISSIONAL E TECNOLÓGICA: UM ESTUDO NO INSTITUTO FEDERAL DE SANTA CATARINA - CÂMPUS XANXERÊ
}

\author{
Julio Cezar Carneiro ${ }^{1}$ \\ Douglas Paulesky Juliani ${ }^{2}$ \\ Sabrina Bleicher ${ }^{3}$
}

\section{RESUMO}

O presente trabalho tem como objetivo identificar as práticas de gestão do conhecimento nas atividades de organização de ensino no Instituto Federal de Santa Catarina - Câmpus Xanxerê. A partir de uma revisão de literatura, foram utilizadas como base para o trabalho, estudos relacionados às conversões de conhecimentos. A pesquisa classifica-se como documental e bibliográfica. Para a coleta de dados, usou-se uma abordagem qualitativa e o instrumento utilizado foi a entrevista semiestruturada. $\mathrm{O}$ trabalho foi desenvolvido no Departamento de Ensino, Pesquisa e Extensão do Instituto Federal de Santa Catarina - Câmpus Xanxerê. Identificou-se que a produção de conhecimento na instituição analisada ocorre principalmente por meio da Combinação e Socialização de conhecimentos, porém não ocorre a externalização de modo formal da produção de material e experiência. Conclui-se que as práticas de Gestão do Conhecimento analisadas ocorrem principalmente de forma individualizada e informal.

Palavras-Chave: Práticas de gestão do conhecimento; Educação profissional e tecnológica; Atividades de organização de ensino.

\begin{abstract}
The present conclusion essay aims to identify the Knowledge management practices in the activities of teaching organization in the Instituto Federal de Santa Catarina Câmpus Xanxerê. From literature review, using as base and interpretation the researches related of the knowledge conversions. The research is classified as documentary and bibliographic. For the data collect was used the qualitative technique, using as instrument the semi-structured interview. The essay was developed in the Department of Teaching, Research and Extension of the Instituto Federal de Santa Catarina - Câmpus Xanxerê. It was identified that the production of knowledge in the analyzed institution occurs mainly through the Combination and Socialization of knowledge, however there is no formal outcoming of the material production and experience. The conclusion was
\end{abstract}

\footnotetext{
${ }^{1}$ Instituto Federal de Educação, Ciência e Tecnologia de Santa Catarina

${ }^{2}$ Instituto Federal de Educação, Ciência e Tecnologia de Santa Catarina

${ }^{3}$ Instituto Federal de Educação, Ciência e Tecnologia de Santa Catarina
} 
that Knowledge management practices occurs, mainly, in an individualized and informal way.

Keywords: Knowledge management practices; Professional and technological education; Activities of teaching organization.

\section{INTRODUÇÃO}

$\mathrm{O}$ estudo do conhecimento humano é tão antigo quanto à própria história do homem, e ao longo dessa jornada, a vitória ficou nas mãos de pessoas que estavam na vanguarda do conhecimento. Atualmente o conhecimento é mais importante do que nunca para a nossa economia, empresas e trabalho. Nosso estoque de capital intelectual é fundamental, pois estamos no meio de uma revolução econômica chamada a Era da Informação (NONAKA, TAKEUCHI, 1997; STEWART, 1998).

Segundo Drucker (2002) o impacto da Revolução da Informação está apenas começando a ser sentido. Cada vez mais percebe-se que a permanência das organizações no mercado, o desenvolvimento de inovações e a melhoria contínua nos processos depende de estruturas organizacionais para a aprendizagem contínua das organizações.

A informação proporciona um novo ponto de vista para a interpretação de objetos, o que torna visíveis significados antes invisíveis, ou lança luz sobre conexões inesperadas. Por isso, a informação é um meio necessário para gerar novos conhecimentos. (NONAKA E TAKEUCHI, 1997; SVEIBY, 1998). Fica-se claro que a informação faz com que novos conhecimentos emerjam, fazendo com que o mesmo evolua, porém é importante que a instituição tenha a estrutura tecnológica adequada para fazer com que a informação se torne conhecimento. Para Fleury e Jr. (2008), essa maior facilidade de acesso à informação, em razão da nova tecnologia e da velocidade das comunicações, criou condições apropriadas para que o conhecimento escapasse de seus pequenos círculos tradicionais.

Nas instituições de ensino, também um novo contexto deve ser analisado. Para Gransci (1982), academias deverão se tornar organizações de sistematização, expansão e criação do conhecimento por meio da iniciativa coletiva e não de indivíduos. Nessas instituições, as atividades de organização de ensino apresentam um papel fundamental no planejamento e efetividade dos objetivos propostos em cada currículo. Vasconcellos 
(2002) corrobora que a prática da organização de ensino dependerá também da concepção de currículo que se tem, tendo em vista as implicações bem concretas em termos de organização do trabalho pedagógico.

Neste sentido, compreende-se que a Gestão do Conhecimento é fundamental para a instituição de ensino conseguir alcançar e evoluir em níveis de conhecimentos cada vez mais elevados e acompanhar a evolução das tecnologias. Considerando o exposto, este estudo destaca a importância do uso de práticas de gestão do conhecimento nas atividades de organização de ensino com foco na Educação Profissional e Tecnológica.

A Educação Profissional e Tecnológica visa garantir à sociedade competências essenciais para o mundo do trabalho. Constantemente, nascem novas tecnologias nas mais diversas áreas de mercado, causando uma pressão na atualização constante de diversas organizações. A adaptação à nova realidade é inevitável, e a Gestão do Conhecimento auxilia nos processos de criação e disseminação do capital intelectual agregado a essas organizações. Assim, o respectivo tema se justifica pela importância do conhecimento nas práticas de organização de ensino como matéria-prima de instituições de ensino, e se torna um fator fundamental para o desenvolvimento e crescimento de todos os envolvidos. A Gestão do Conhecimento, consequentemente, deve ser um processo organizado e sistematizado institucionalmente, no qual pode tornar os processos de aprendizagem mais eficientes. Dada a relevância da gestão do conhecimento nas atividades de organização de ensino na Educação Profissional e Tecnológica, faz-se o problema de pesquisa:

Quais as práticas de Gestão do Conhecimento são utilizadas nas atividades de organização de ensino no Instituto Federal de Santa Catarina - Câmpus Xanxerê?

Para responder a esta pergunta, o presente trabalho tem como objetivo identificar as práticas de Gestão do Conhecimento nas atividades de organização de ensino no Instituto Federal de Santa Catarina - Câmpus Xanxerê. Para a efetividade do estudo é fundamental compreender as atividades de organização de ensino, entender as práticas de Gestão do Conhecimento e identificar as práticas de Gestão do Conhecimento nas atividades de organização de ensino na instituição pesquisada. 


\section{REFERENCIAL TEÓRICO}

\section{Atividades de organização de ensino na Educação Profissional e Tecnológica}

Pode-se dizer que a atividade de organização de ensino é o planejamento para a execução do desenvolvimento pedagógico dos docentes. Num sentido mais geral, a atividade tipicamente humana e consciente, está constantemente marcada por um ato de planejamento. Planejar, de alguma forma, com maior ou menor rigor, o professor sempre planeja seja por escrito, mental ou oralmente (VASCONCELLOS, 2002).

Para Falconi (2009) o conhecimento é adquirido pela prática da análise e da síntese das informações na fase de planejamento. Com a argumentação do autor, podese notar a importância da organização e planejamento das atividades de ensino na Educação Profissional e Tecnológica.

O planejamento mais especificamente pedagógico diz respeito ao trabalho em sala de aula, no qual acontece a interação entre os sujeitos e a construção do conhecimento. Segundo Vasconcellos (2002), a prática do planejamento dependerá também da concepção de currículo que se tem, tendo em vista as implicações bem concretas em termos de organização. O mesmo autor, corrobora que um currículo reflete não só a natureza do conhecimento em si mesmo, como também a natureza do conhecedor e do processo de aquisição do conhecimento. Esse conhecimento adquirido e acumulado, muitas vezes é feito por uma tendência concebida por educadores que rompem concepções tradicionais e buscam realizar um trabalho mais significativo, muitas vezes dentro de uma estrutura burocrática.

As atividades docentes do Instituto Federal de Educação, Ciência e Tecnologia de Santa Catarina - IFSC, foram aprovadas segundo a Resolução No 23/2014 no qual a presidente do Conselho Superior do Instituto Federal de Santa Catarina considera o processo de debates realizado pela comunidade acadêmica e a tramitação das propostas pelos Colegiados competentes (IFSC, 2017).

Encontram-se no Art. $3^{\circ}$ as atividades que serão consideradas para a distribuição da carga horária docente: I) Atividades de ensino; II) Atividades de pesquisa; III) Atividades de extensão; IV) Atividades de gestão e representação; V) Atividades de capacitação e qualificação. Serão consideradas atividades de ensino, conforme Art. $5^{\circ}$ : I) Ministrar aulas; II) Organizar o ensino; III) Realizar atividades de apoio ao ensino. Já 
no Art. $6^{\circ}$, constam as informações centrais que nortearão o respectivo trabalho, e traz as atividades de organização de ensino na Educação Profissional e Tecnológica: I) Elaboração de plano de ensino e/ou aula; II) Preparação de aulas; III) Produção e correção de instrumentos de avaliação; IV) Registro de informações acadêmicas.

O início da organização de ensino é a preparação do plano de ensino e/ou aula. Para Vasconcellos (2002), plano de aula é a proposta de trabalho do professor para uma determinada aula ou conjunto de aulas. Já o plano de ensino está atrelado a uma concepção de educação, que por sua vez, está relacionada às concepções de conhecimento e currículo. Para o autor, pensar no plano de ensino é pensar sobre o campo de atuação do docente, e refletir sobre o que se entende por educação escolar e qual é o papel da escola. Desde o início, o docente deve ir em busca de novos aprendizados, e da atualização constante dos conteúdos, assim como Falconi (2009) corrobora que, dentro de uma organização, uma pessoa deve ser constantemente desafiada a buscar conhecimento novo.

A atividade de preparação de aulas é essencial para o aprendizado do aluno, sendo que se o professor não estiver consciente dos conteúdos que abordará, poderá correr o risco de perder o foco das aulas e não conseguir ensinar os alunos adequadamente. Para Nonaka e Takeuchi (1997) os colaboradores podem se tornar tão escravos de suas próprias e limitadas perspectivas que perdem a visão do contexto maior. Muitas vezes, a preparação de aulas não tem o mínimo de compartilhamento, ainda Nonaka e Takeuchi (1997) justificam que essa troca de conhecimento não acontece principalmente por achar difícil comunicar a importância da informação para outros. Vasconcellos (2002) complementa que o conhecimento por parte do professor parece uma coisa tão óbvia que muitas vezes nem é explicitado. O posicionamento claro do professor é fundamental e relevante frente a tantos desafios e dificuldades. Ainda Vasconcellos (2002) corrobora que, o que estamos buscando agora é uma forma mais adequada à realidade educacional, na superação tanto do planejamento espontâneo, quanto o formal.

Os registros de informações acadêmicas são fundamentais para a explicitação do conhecimento adquirido por meio dos erros e acertos. Para Senge (1998) ocorre frustração nos contextos em que as equipes buscam desenvolver capacidades de aprendizagem, em projetos que começam e não criam raízes ou são abandonados depois 
de alguns meses. Principalmente, é no registro de informações acadêmicas que o docente verificará se a execução foi conforme o planejamento. É nesse processo que o feedback deverá ocorrer. Senge (1998) aborda que se você está num sistema de feedback, pode não perceber como as pequenas ações podem evoluir transformando-se em grandes consequências, para melhor ou para pior. Falconi (2009) reforça sobre o feedback negativo, e corrobora que, entre outros aspectos, falhamos por que não executamos completamente, e a tempo, o que foi planejado e podem ocorrer circunstâncias fora de nosso controle.

\section{A gestão do conhecimento, o planejamento e a organização do ensino}

A vitória de uma organização, seja ela uma escola, um hospital, uma prefeitura, uma empresa ou até mesmo o Governo Federal, é algo desejado por todos e, quando acontece, é uma grande fonte de alegria e satisfação (FALCONI, 2009). Essa vitória está cada vez mais nas mãos de quem detém e acumula mais conhecimento. Drucker (1993) sugeriu que um dos desafios mais importantes às organizações da sociedade do conhecimento é desenvolver práticas sistemáticas para administrar a autotransformação. A organização, seja ela de qualquer segmento, tem que estar preparada para abandonar o conhecimento obsoleto e aprender a criar o novo.

O tema gestão do conhecimento emergiu na última década, das discussões fechadas entre pesquisadores de diferentes áreas das empresas, para despontar como um dos assuntos mais polêmicos e menos compreendidos (FLEURY e JR., 2008). Segundo Bateman (2012): "um dos processos mais importantes da gestão do conhecimento é garantir a eficácia da colaboração entre pessoas em diferentes partes da organização". Sobre a colaboração, Senge (1998) corrobora que quando as atividades de organização de ensino são desenvolvidas em conjunto, tem um impacto significativo e mensurável sobre o desempenho. Para Fleury e Jr. (2008) o conhecimento fundamenta-se não no indivíduo, mas na distribuição de um grupo de pessoas que trabalham juntas.

Nonaka e Takeuchi (1997) abordam o conhecimento em dois tipos: conhecimento tácito e conhecimento explícito. Fleury e Jr. (2008) abordam que o conhecimento tácito é baseado na prática, está disponível, é distribuído e improvisado. Já o conhecimento explícito ou codificado refere-se ao conhecimento transmissível em 
linguagem formal e sistemática. O conhecimento explícito é mais simples de ser codificado e formal, diz respeito às crenças e compromissos, atitudes, perspectivas ou intenções específicas.

Segundo Falconi (2009) uma organização que busca cada vez mais, melhores resultados por meio de todas as pessoas acabam por gerar uma quantidade enorme de conhecimento que deve ser gerenciado. Esse conhecimento acumulado, segundo Fleury e Jr. (2008) deve ter a sua existência apoiada e reconhecida. Não se trata de equipes ou unidades identificadas em um organograma. Ao contrário, são grupos que desenvolvem espontaneamente em torno de práticas compartilhadas. Bateman e Snell (2012) complementam que essas práticas objetivam identificar e compartilhar os recursos intelectuais de uma organização e as competências individuais que nela existem.

As práticas de Gestão do Conhecimento auxiliam na criação, compartilhamento e disseminação do conhecimento. Nonaka e Takeuchi (1997) classificam essas práticas como "Conversão de Conhecimento", onde acontece a interação e a transformação dos tipos de conhecimentos. Segundo os autores, esse processo acontece por meio de 4 etapas apresentadas abaixo:

- Socialização: de conhecimento tácito em conhecimento tácito; processo de compartilhamento de experiências, criação do conhecimento tácito por meio de modelos mentais e habilidades técnicas compartilhadas, utiliza-se o brainstorming como ferramenta para essa prática;

- Externalização: de conhecimento tácito em conhecimento explícito, processo de criação do conhecimento na medida em que o conhecimento tácito se torna explícito, é a chave para a criação do conhecimento, pois cria conhecimentos novos e explícitos a partir do conhecimento tácito, metáforas, analogias e hipóteses são utilizadas nesse tipo de conversão de conhecimento;

- Combinação: de conhecimento explícito em conhecimento explícito), processo de sistematização de conceitos em um sistema de conhecimento, no qual envolve a combinação de diferentes conjuntos de conhecimento explícito, utiliza-se para essa conversão a troca e combinação de documentos, reuniões, conversas ao telefone e redes de comunicação computadorizadas;

- Internalização: de conhecimento explícito para conhecimento tácito, relacionado ao aprender fazendo. Quando são internalizadas nas bases do 
conhecimento tácito dos indivíduos sob a forma de modelos mentais ou knowhow técnico compartilhado, as experiências através da socialização, externalização e combinação tornam-se ativos valiosos.

É importante ressaltar que a Combinação de conhecimentos acumulados por meio de troca e combinação de documentos, estruturando um banco de dados em redes de comunicação computadorizadas é fundamental para o aprendizado nas instituições de ensino, porém, Fleury e Jr. (2008) afirmam que uma das dificuldades de desenvolver tais bancos de dados é que se tornam rapidamente saturados, perdendo a especificidade e o valor na proporção de seu crescimento indiscriminado. Para os autores, para um banco de dados permanecer útil, a alimentação do banco de dados precisa ser criteriosamente filtrada conforme seus próprios julgamentos.

Segundo Fleury e Jr. (2008) mudanças importantes aconteceram no final deste século, entre as mais importantes refere-se à maneira como o conhecimento científico vem sendo usado pelas instituições e pela sociedade. Nota-se a nova realidade e o novo cenário em que as organizações sofrem uma pressão enorme para se adaptar à nova matéria-prima da sociedade, o conhecimento. Essas mudanças, devem ocorrer primeiramente na estrutura de criação de conhecimento, onde acontece os primeiros processos de organização das atividades de ensino dos docentes, ou seja, o planejamento. Vasconcellos (2002) defende que temos que mudar a mentalidade de que fazer planejamento é preencher formulários. Afirma que em muitas situações o professor não é sujeito de seu planejamento, à medida que acaba se limitando a recursos didáticos específicos. Conclui corroborando que fazer planejamento é refletir sobre os desafios da realidade da instituição e da sala de aula, perceber as necessidades e comprometer-se com a transformação da prática.

\section{PERCURSO METODOLÓGICO}

O trabalho desenvolvido enquadra-se aos fins de investigação, como uma pesquisa descritiva pelo fato de descrever as práticas de Gestão do Conhecimento em atividades de organização de ensino. As pesquisas descritivas têm como objetivo a descrição das características de determinado fenômeno (GIL, 2008). 
Em relação aos meios de investigação, a pesquisa classifica-se como documental e bibliográfica. Para Lakatos e Marconi (2003) a fonte da pesquisa documental está restrita a documentos, escritos ou não, constituindo o que se denomina de fontes primárias. Já a pesquisa bibliográfica, para os mesmos autores, abrange toda bibliografia já tornada pública em relação ao tema de estudo. A coleta de dados foi conduzida no Instituto Federal de Santa Catarina - Câmpus Xanxerê, na cidade de Xanxerê, localizado no Oeste de Santa Catarina.

Para a coleta de dados, usou-se a técnica qualitativa e o instrumento utilizado foi a entrevista semiestruturada. A entrevista foi conduzida e registrada por meio de um roteiro de perguntas em um formulário em um computador pessoal. Para Gil (2008), o modo mais confiável de reproduzir com precisão as respostas é registrá-las durante a entrevista. Por se tratar de uma entrevista semiestruturada, as perguntas foram abertas, e a interpretação dos dados foi feita simultaneamente, destacando os processos de transferência de conhecimento, e registrando as respostas diretamente no formulário em perguntas fechadas e voltadas ao objetivo do respectivo trabalho. Participaram da entrevista, como amostra, 16 indivíduos de uma população de 25 docentes dos Núcleos do Ensino Médio e da Educação Profissional atuantes no semestre 2017-1, nos seguintes eixos tecnológicos: informação e comunicação, produção alimentícia e controle e processos industriais. $\mathrm{O}$ âmbito do estudo foi delimitado às atividades de organização de ensino dos docentes, e o assunto às práticas de gestão do conhecimento.

\section{RESULTADOS E DISCUSSÃO}

O Instituto Federal de Santa Catarina (IFSC) é uma instituição pública federal vinculada ao Ministério da Educação (MEC) por meio da Secretaria de Educação Profissional e Tecnológica (SETEC). Tem sede e foro em Florianópolis, com autonomia administrativa, patrimonial, financeira, didático-pedagógico e disciplinar. Tem como missão promover a inclusão e formar cidadãos, por meio da educação profissional, científica e tecnológica, gerando, difundindo e aplicando conhecimento e inovação, contribuindo para o desenvolvimento socioeconômico e cultural (IFSC, 2017).

O Câmpus Xanxerê do Instituto Federal de Santa Catarina é fruto da federalização do Centro Metal Mecânico de Xanxerê. A estrutura física do centro, foi 
construída com recursos do FNDE e PROEP, tendo como objetivo a oferta de cursos técnicos para atender a demanda da região. Em 2005, iniciou-se um movimento para que a estrutura fosse federalizada e se transformasse numa escola pública com oferta de cursos gratuitos. Atendendo às reivindicações da região, o IFSC iniciou o processo de implantação do Câmpus Avançado em março de 2009. Em julho de 2011, iniciaram as aulas dos dois primeiros cursos técnicos do Câmpus: Técnico em Agroindústria e Técnico em Fabricação Mecânica. Em 2014, deixou de ser Câmpus Avançado e passou a ser chamado IFSC Câmpus Xanxerê ofertando além de cursos Técnicos Profissionais, cursos de Formação Inicial e Continuada - FICs e cursos PRONATEC. Em 2016, o Câmpus iniciou o curso de Graduação em Engenharia Mecânica e os Cursos Técnicos Integrados em Alimentos e Informática, com novas perspectivas para os próximos anos. O número de docentes aumentou mais que a metade desde 2014, e o acúmulo de conhecimento é cada vez maior nos diferentes Eixos Tecnológicos do Câmpus.

O trabalho de mapeamento de práticas de gestão do conhecimento nas atividades de organização de ensino na EPT foi desenvolvido com a análise de 16 entrevistas semiestruturadas, nas quais os docentes do Instituto Federal de Santa Catarina Câmpus Xanxerê concordaram em participar. Os resultados serão apresentados neste trabalho, separadamente, em duas etapas: primeiramente, será identificada a amostra entrevistada para conhecimento do perfil dos docentes, para que a segunda etapa analise e apresente, em cada atividade de organização de ensino do docente, as práticas de gestão do conhecimento identificadas na sua rotina, junto com observações e complementos teóricos.

Observa-se a amostra analisada no Gráfico 1 e nota-se a quantidade de variação de áreas de formação dos docentes. Acredita-se que essa variação qualifica a pesquisa por ampliar os resultados das atividades de organização de ensino do Câmpus. 
Gráfico 1 - Área de formação dos docentes

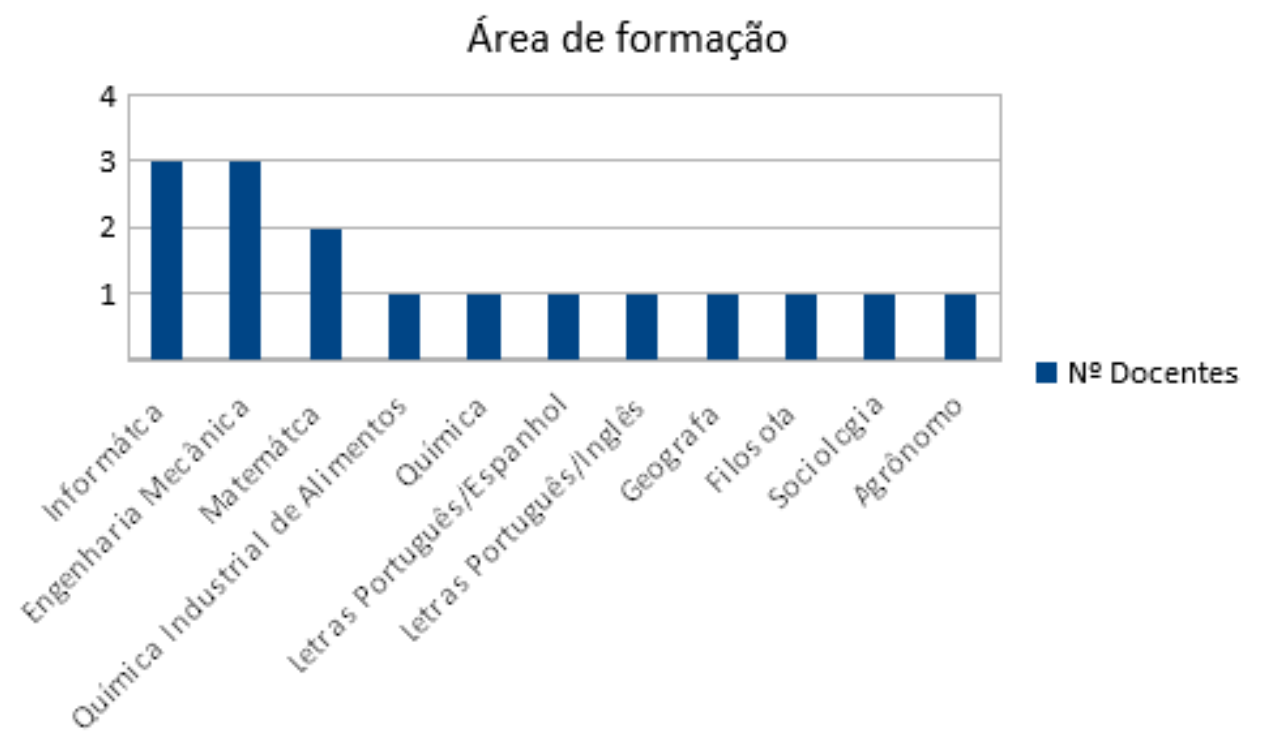

Fonte: Elaborado pelos autorer.

Sobre os Eixo(s) Tecnológico(s) de atuação dos docentes, observa-se no Gráfico 2 que 11 (68,8\%) docentes atuam no Eixo Tecnológico de Informação e Comunicação, no qual engloba o Curso Técnico em Informática Integrado ao Ensino Médio.

Gráfico 2 - Eixo(s) Tecnológico(s) de atuação dos docentes

\section{Eixo(s) Tecnológico(s) de atuação}

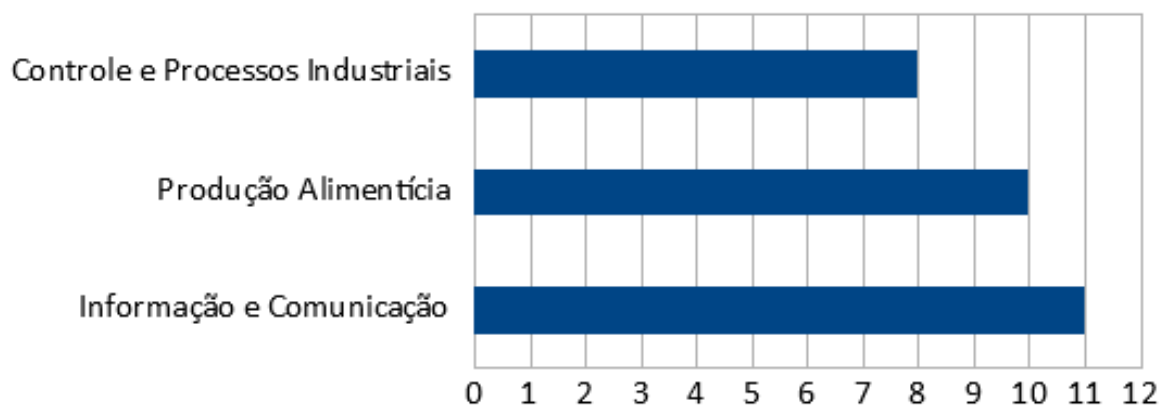

Fonte: Elaborador pelos autores. 
Na Produção Alimentícia analisou-se 10 (62,5\%) docentes que ministram aulas no Curso Técnico em Alimentos Integrado em ao Ensino Médio. Já em Controle e Processos Industriais, que englobam o Curso Técnico em Mecânica e a Graduação em Engenharia Mecânica, foram entrevistados 8 (50\%) docentes. É importante salientar que diversos docentes efetuam as atividades de organização de ensino para mais de um Eixo Tecnológico, no qual se encontram contabilizados no respectivo gráfico.

Já sobre a escolaridade da amostra analisada, salienta-se no Gráfico 3 que 8 docentes $(50 \%)$ possuem mestrado, $6(37,5 \%)$ finalizaram o doutorado, e $2(12,5 \%)$ a especialização.

Gráfico 3: Escolaridade dos docentes

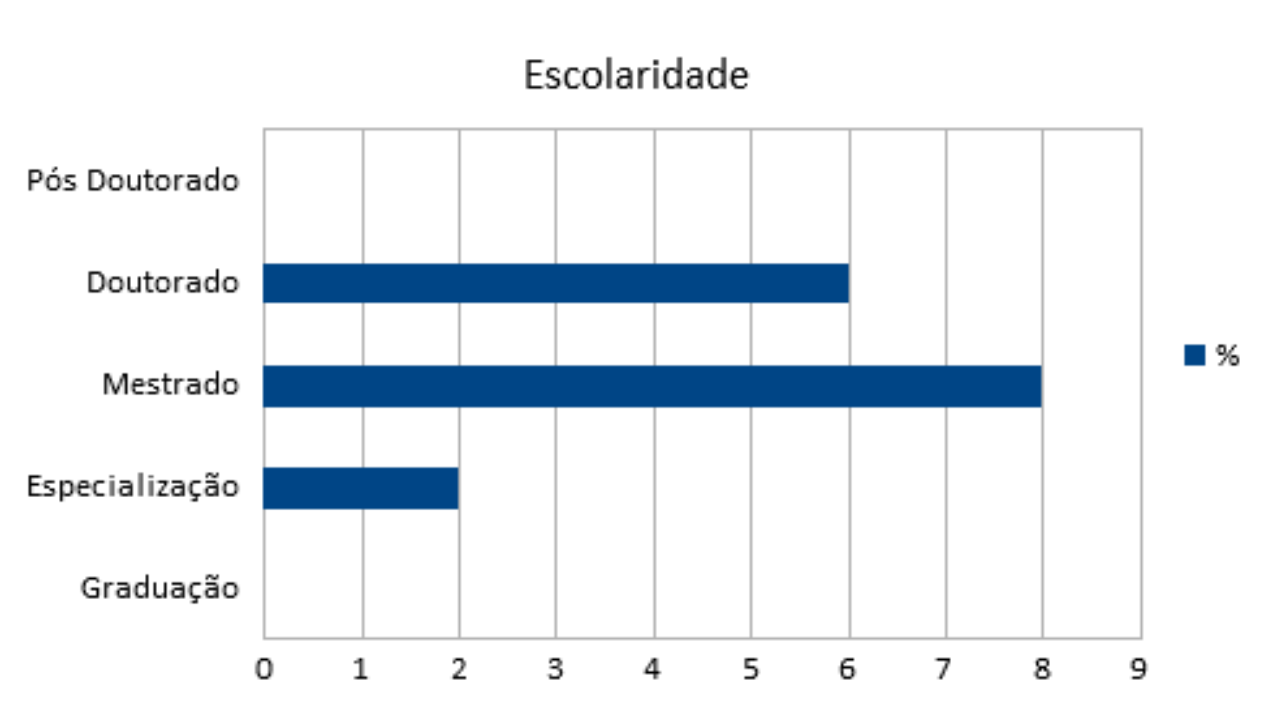

Fonte: Elaborado pelos autores.

\section{PRÁTICAS DE GESTÃO DO CONHECIMENTO NAS ATIVIDADES DE ORGANIZAÇÃO DE ENSINO SEGUNDO A RESOLUÇÃO N 23}

Apresenta-se então os dados obtidos nas entrevistas separados a partir de cada atividade de organização de ensino segundo a resolução $\mathrm{N}^{\circ} 23$. Na produção de material, serão analisados três aspectos referentes a cada atividade: o desenvolvimento do material de um Componente Curricular que o docente nunca ministrou (entrada de conhecimento), o desenvolvimento do material de um Componente Curricular já ministrado pelo docente entrevistado (entrada de conhecimento), e se alguma vez o 
docente já compartilhou a experiência e/ou material desenvolvido (saída de conhecimento).

\section{ELABORAÇÃO DE PLANO DE ENSINO}

Como atividade de organização de ensino, o docente possui a responsabilidade da elaboração de Plano de Ensino. O mapeamento das práticas de Gestão do Conhecimento voltado a essa atividade mostrou, conforme o Quadro 1 que a sua elaboração parte de Conhecimento Explícito em Conhecimento Explícito, isso quer dizer que a busca de conhecimentos, segundo Nonaka e Takeuchi (1997), parte de documentos, reuniões ou redes de comunicação computadorizadas. Após a Combinação, o docente utiliza a Socialização e a Internalização, no qual não aprendem através da linguagem, mas sim através da prática. Em contrapartida, não há algum processo formal para o compartilhamento da experiência e/ou material desenvolvido, a Conversão de conhecimento acontece informalmente por meio de práticas aleatórias e oportunas, além de uma porcentagem significativa que aponta para o não acontecimento de nenhum tipo de compartilhamento de experiência. Por ser uma conversão de saída de conhecimento do docente, a Externalização não se aplica para adquirir novos conhecimentos na elaboração do material de Componente Curricular novo e já ministrado. O mesmo acontece com a internalização, no qual é um processo de entrada de conhecimento ao docente, e não de compartilhamento da experiência e saída do conhecimento por parte do mesmo. E não se aplica também o compartilhamento de experiência do material desenvolvido quando se fala em buscar conhecimento para o seu desenvolvimento.

\section{PREPARAÇÃO DE AULAS}

A Conversão e articulação de conhecimento por meio da Combinação, também faz parte de forma significativa na atividade de organização de ensino de preparação de aulas dos docentes, conforme demonstra o Quadro 2, seguidos da Socialização e da Internalização do Conhecimento. Segundo Nonaka e Takeuchi (1997), a Internalização é o processo de incorporação do conhecimento explícito no conhecimento tácito, e faz com que as experiências através da socialização, externalização e combinação tornamse ativos valiosos. Entende-se então que para que a Internalização aconteça, as outras 
conversões devem acontecer de forma sistematizada. O compartilhamento das experiências e materiais das aulas mostra-se fraca, não havendo nenhum tipo de compartilhamento de experiência ou acontecendo apenas informalmente. As considerações das não aplicações em alguns casos seguem as mesmas da subseção Elaboração de Plano de Ensino.

Quadro 1: Compartilhamento de conhecimentos para a elaboração de Plano de Ensino

\begin{tabular}{|c|c|c|c|}
\hline $\begin{array}{l}\text { Descrição da Conversão e práticas de } \\
\text { articulação de conhecimento }\end{array}$ & $\begin{array}{l}\text { Plano de } \\
\text { Ensino de } \\
\text { Componente } \\
\text { Curricular } \\
\text { Novo }\end{array}$ & $\begin{array}{l}\text { Plano de } \\
\text { Ensino de } \\
\text { Componente } \\
\text { Curricular já } \\
\text { ministrado } \\
\text { pelo docente }\end{array}$ & $\begin{array}{l}\text { Compartilhamento } \\
\text { da experiência e/ou } \\
\text { material } \\
\text { desenvolvido }\end{array}$ \\
\hline $\begin{array}{l}\text { Buscar informações por meio de conversas e } \\
\text { reuniões formais e/ou informais com } \\
\text { pessoas específicas da área; } \\
\text { Compartilhamento de experiências - } \\
\text { Socialização (Conhecimento tácito em } \\
\text { conhecimento tácito). }\end{array}$ & $50 \%$ & $31,3 \%$ & Não se aplica. \\
\hline $\begin{array}{l}\text { Criar e escrever novos conceitos formais e } \\
\text { explícitos por meio da reflexão coletiva de } \\
\text { aprendizados e experiências } \\
\text { Externalização (Conhecimento tácito em } \\
\text { conhecimento explícito). }\end{array}$ & Não se aplica. & Não se aplica. & $12,5 \%$ \\
\hline $\begin{array}{l}\text { Trocar e Combinar aprendizados de práticas } \\
\text { e conceitos por meio de documentos e } \\
\text { reuniões - Combinação (Conhecimento } \\
\text { explícito em conhecimento explícito). }\end{array}$ & $100 \%$ & $100 \%$ & $18,8 \%$ \\
\hline $\begin{array}{l}\text { Aprender na prática o conhecimento } \\
\text { explícito por meio do compartilhamento de } \\
\text { experiências, documentos e reuniões - } \\
\text { Internalização (Conhecimento explícito em } \\
\text { conhecimento tácito). }\end{array}$ & $25 \%$ & $25 \%$ & Não se aplica. \\
\hline $\begin{array}{l}\text { Não acontece nenhum tipo de } \\
\text { compartilhamento de experiência. }\end{array}$ & Não se aplica. & Não se aplica. & $37,5 \%$ \\
\hline $\begin{array}{l}\text { Outro (Conversão de conhecimento que } \\
\text { acontece informalmente). }\end{array}$ & $12,6 \%$ & $6,3 \%$ & $56,5 \%$ \\
\hline
\end{tabular}

Fonte: Elaborado pelos autores. 
Quadro 2: Compartilhamento de conhecimentos para a preparação de aulas

\begin{tabular}{|c|c|c|c|}
\hline $\begin{array}{l}\text { Conversão e práticas de articulação de } \\
\text { conhecimento }\end{array}$ & $\begin{array}{l}\text { Preparação } \\
\text { de aulas de } \\
\text { Componente } \\
\text { Curricular } \\
\text { Novo }\end{array}$ & $\begin{array}{l}\text { Preparação } \\
\text { de aulas de } \\
\text { Componente } \\
\text { Curricular já } \\
\text { ministrado } \\
\text { pelo docente }\end{array}$ & $\begin{array}{l}\text { Compartilhamento } \\
\text { da experiência e/ou } \\
\text { material } \\
\text { desenvolvido }\end{array}$ \\
\hline $\begin{array}{l}\text { Buscar informações por meio de conversas } \\
\text { e reuniões formais e/ou informais com } \\
\text { pessoas específicas da área; } \\
\text { Compartilhamento de experiências - } \\
\text { Socialização (Conhecimento tácito em } \\
\text { conhecimento tácito). }\end{array}$ & $68,8 \%$ & $37,5 \%$ & Não se aplica. \\
\hline $\begin{array}{l}\text { Criar e escrever novos conceitos formais e } \\
\text { explícitos por meio da reflexão coletiva de } \\
\text { aprendizados e experiências - } \\
\text { Externalização (Conhecimento tácito em } \\
\text { conhecimento explícito). }\end{array}$ & Não se aplica. & Não se aplica. & $12,5 \%$ \\
\hline $\begin{array}{l}\text { Trocar e Combinar aprendizados de } \\
\text { práticas e conceitos por meio de } \\
\text { documentos e reuniões - Combinação } \\
\text { (Conhecimento explícito em conhecimento } \\
\text { explícito). }\end{array}$ & $93,8 \%$ & $93,8 \%$ & $18,8 \%$ \\
\hline $\begin{array}{l}\text { Aprender na prática o conhecimento } \\
\text { explícito por meio do compartilhamento } \\
\text { de experiências, documentos e reuniões - } \\
\text { Internalização (Conhecimento explícito } \\
\text { em conhecimento tácito). }\end{array}$ & $18,8 \%$ & $25 \%$ & Não se aplica. \\
\hline $\begin{array}{l}\text { Não acontece nenhum tipo de } \\
\text { compartilhamento de experiência. }\end{array}$ & Não se aplica. & Não se aplica. & $56,3 \%$ \\
\hline $\begin{array}{l}\text { Outro (Conversão de conhecimento que } \\
\text { acontece informalmente). }\end{array}$ & $6,3 \%$ & $6,3 \%$ & $37,6 \%$ \\
\hline
\end{tabular}

Fonte: Elaborado pelos autores.

\section{PRODUÇÃO E CORREÇÃO DE INSTRUMENTOS DE AVALIAÇÃO}

Na produção e correção de instrumentos de avaliação, conforme o Quadro 3, os docentes buscam principalmente os materiais por meio de Combinação. Isso significa que a principal fonte de coleta de informações são materiais já preparados, seja pela internet, banco de dados, livros e revistas para componentes curriculares novos ou já ministrados pelo docente. Porém notou-se a tendência do não compartilhamento da 
experiência e/ou material desenvolvido, portanto a Externalização destes materiais não acontece, e resume-se que tudo que o docente produz não é compartilhado, fazendo o seu próprio banco de dados individualizado. Consequentemente, a Socialização e a Internalização do conhecimento acabam se tornando secundário, fazendo com que todo o conhecimento gerado não seja disseminado. As considerações das não aplicações em alguns casos seguem as mesmas da subseção Elaboração de Plano de Ensino.

Quadro 3: Compartilhamento de conhecimentos a produção e correção de instrumentos de avaliação

\begin{tabular}{|c|c|c|c|}
\hline Conversão e articulação de conhecimento & $\begin{array}{l}\text { Produção e } \\
\text { correção de } \\
\text { instrumentos } \\
\text { de avaliação } \\
\text { de } \\
\text { Componente } \\
\text { Curricular } \\
\text { Novo }\end{array}$ & $\begin{array}{l}\text { Produção e } \\
\text { correção de } \\
\text { instrumentos } \\
\text { de avaliação de } \\
\text { Componente } \\
\text { Curricular já } \\
\text { ministrado } \\
\text { pelo docente }\end{array}$ & $\begin{array}{l}\text { Compartilhamento } \\
\text { da experiência e/ou } \\
\text { material } \\
\text { desenvolvido }\end{array}$ \\
\hline $\begin{array}{l}\text { Buscar informações por meio de conversas e } \\
\text { reuniões formais e/ou informais com pessoas } \\
\text { específicas da área; Compartilhamento de } \\
\text { experiências - Socialização (Conhecimento } \\
\text { tácito em conhecimento tácito). }\end{array}$ & $33,3 \%$ & $14,3 \%$ & Não se aplica. \\
\hline $\begin{array}{l}\text { Criar e escrever novos conceitos formais e } \\
\text { explícitos por meio da reflexão coletiva de } \\
\text { aprendizados e experiências - Externalização } \\
\text { (Conhecimento tácito em conhecimento } \\
\text { explícito). }\end{array}$ & Não se aplica. & Não se aplica. & $13,3 \%$ \\
\hline $\begin{array}{l}\text { Trocar e Combinar aprendizados de práticas e } \\
\text { conceitos por meio de documentos e reuniões - } \\
\text { Combinação (Conhecimento explícito em } \\
\text { conhecimento explícito). }\end{array}$ & $100 \%$ & $100 \%$ & $20 \%$ \\
\hline $\begin{array}{l}\text { Aprender na prática o conhecimento explícito } \\
\text { por meio do compartilhamento de } \\
\text { experiências, documentos e reuniões - } \\
\text { Internalização (Conhecimento explícito em } \\
\text { conhecimento tácito). }\end{array}$ & $20 \%$ & $14,3 \%$ & Não se aplica. \\
\hline $\begin{array}{l}\text { Não acontece nenhum tipo } \quad \text { de } \\
\text { compartilhamento de experiência. }\end{array}$ & Não se aplica. & Não se aplica. & $46,7 \%$ \\
\hline $\begin{array}{l}\text { Outro (Conversão de conhecimento que } \\
\text { acontece informalmente). }\end{array}$ & $0 \%$ & $0 \%$ & $40 \%$ \\
\hline
\end{tabular}

Fonte: Elaborado pelos autores. 


\section{REGISTROS DE INFORMAÇÕES ACADÊMICAS}

Para identificar o modo geral de preenchimento e da busca de soluções de problemas quando os docentes sentiam dificuldades no preenchimento dos registros de informações acadêmicas, foram feitos também questionamentos voltados aos sistemas que englobam as atividades de organização de ensino: PSAD - . Constatou-se que a busca de soluções ocorre principalmente por processos de compartilhamento de experiências dos docentes (Socialização: Conhecimento Tácito em Conhecimento Tácito). Isso significa que as soluções são adquiridas diretamente de outros docentes por troca de informações voltadas as experiências de cada um. A busca de soluções por meio de manuais acontece, porém de forma mínima e secundária, conforme demonstram os dados do Quadro 4.

No estudo, a amostra foi também questionada sobre o compartilhamento da experiência após o registro de informações acadêmicas. Pode-se analisar o mapeamento dos resultados no Quadro 5, no qual demonstra de forma clara que há o mínimo do processo de Externalização do conhecimento. Segundo Nonaka e Takeuchi (1997) o conhecimento é criado de forma dinâmica na interação social entre as pessoas. Portanto, pode-se dizer que o conhecimento é limitado aos indivíduos que o aprendem. Quando questionados sobre a Combinação do conhecimento, acontece de forma mínima e contínua a sua troca por meio de documentos e reuniões. E por fim, torna-se evidente conforme as informações, que o índice em que não acontece nenhum tipo de compartilhamento de experiência é alto, assim como o compartilhamento de conhecimentos de forma informal e não sistematizado.

Portanto, fica-se claro que o compartilhamento de conhecimento acontece principalmente por meio da Socialização (Conhecimento Tácito em Conhecimento Tácito), onde os indivíduos estão diretamente ligados com a fonte de conhecimento. 
Quadro 4: Ação que efetua caso sinta dificuldades de preenchimento nos registros de informações acadêmicas

Mapeamento do modo geral de preenchimento e de busca de soluções caso sinta dificuldades nos registros de informações acadêmicas

\begin{tabular}{|c|c|c|c|c|}
\hline Descrição & $\begin{array}{l}\text { Planos } \\
\text { Semestrais de } \\
\text { Atividades } \\
\text { Docentes } \\
\text { (PSAD) }\end{array}$ & $\begin{array}{l}\text { Relatórios } \\
\text { Semestrais de } \\
\text { Atividades } \\
\text { Docentes } \\
\text { (RSAD) }\end{array}$ & $\begin{array}{l}\text { Diário de } \\
\text { Classe }\end{array}$ & $\begin{array}{c}\text { Sistema } \\
\text { Acadêmico }\end{array}$ \\
\hline $\begin{array}{l}\text { Buscar informações por meio de } \\
\text { conversas e reuniões formais e/ou } \\
\text { informais com pessoas específicas da } \\
\text { área; Compartilhamento de experiências } \\
\text { - Socialização (Conhecimento tácito em } \\
\text { conhecimento tácito). }\end{array}$ & $87,5 \%$ & $87,5 \%$ & $93,3 \%$ & $100 \%$ \\
\hline $\begin{array}{l}\text { Criar e escrever novos conceitos formais } \\
\text { e explícitos por meio da reflexão coletiva } \\
\text { de aprendizados e experiências - } \\
\text { Externalização (Conhecimento tácito em } \\
\text { conhecimento explícito). }\end{array}$ & Não se aplica. & Não se aplica. & Não se aplica. & Não se aplica. \\
\hline $\begin{array}{l}\text { Trocar e Combinar aprendizados de } \\
\text { práticas e conceitos por meio de } \\
\text { documentos e reuniões - Combinação } \\
\text { (Conhecimento explícito em } \\
\text { conhecimento explícito). }\end{array}$ & Não se aplica. & Não se aplica. & Não se aplica. & Não se aplica. \\
\hline $\begin{array}{l}\text { Aprender na prática o conhecimento } \\
\text { explícito por meio do compartilhamento } \\
\text { de experiências, documentos e reuniões - } \\
\text { Internalização (Conhecimento explícito } \\
\text { em conhecimento tácito). }\end{array}$ & $37,5 \%$ & $37,5 \%$ & $33,3 \%$ & $21,4 \%$ \\
\hline Outro & $0 \%$ & $0 \%$ & $0 \%$ & $0 \%$ \\
\hline
\end{tabular}

Fonte: Elaborado pelos autores.

\section{CONSIDERAÇÕES FINAIS}

O respectivo trabalho teve por objetivo identificar as práticas de Gestão do Conhecimento nas atividades de organização de ensino no Instituto Federal de Santa Catarina - Câmpus Xanxerê. A instituição que norteou o desenvolvimento deste estudo está inserida no setor de educação, portanto possui como matéria-prima o capital 
intelectual. As práticas de gestão do conhecimento devem ocorrer de modo formal e sistematizado, o acúmulo de informação na instituição tem um valor intangível, ainda mais tendo como matéria-prima o conhecimento.

Quadro 5: Compartilhamento da experiência após o registro de informações em cada atividade de organização de ensino

Compartilhamento da experiência após o registro de informações acadêmicas.

\begin{tabular}{|c|c|c|c|c|}
\hline Descrição & $\begin{array}{l}\text { Planos } \\
\text { Semestrais de } \\
\text { Atividades } \\
\text { Docentes } \\
\text { (PSAD) }\end{array}$ & $\begin{array}{l}\text { Relatórios } \\
\text { Semestrais de } \\
\text { Atividades } \\
\text { Docentes } \\
\text { (RSAD) }\end{array}$ & $\begin{array}{l}\text { Diário de } \\
\text { Classe }\end{array}$ & $\begin{array}{c}\text { Sistema } \\
\text { Acadêmico }\end{array}$ \\
\hline $\begin{array}{l}\text { Buscar informações por meio de conversas e } \\
\text { reuniões formais e/ou informais com pessoas } \\
\text { específicas da área; Compartilhamento de } \\
\text { experiências - Socialização (Conhecimento } \\
\text { tácito em conhecimento tácito). }\end{array}$ & Não se aplica. & Não se aplica. & $\begin{array}{l}\text { Não se } \\
\text { aplica. }\end{array}$ & $\begin{array}{l}\text { Não se } \\
\text { aplica. }\end{array}$ \\
\hline $\begin{array}{l}\text { Criar e escrever novos conceitos formais e } \\
\text { explícitos por meio da reflexão coletiva de } \\
\text { aprendizados e experiências - Externalização } \\
\text { (Conhecimento tácito em conhecimento } \\
\text { explícito). }\end{array}$ & $0 \%$ & $0 \%$ & $6,3 \%$ & $0 \%$ \\
\hline $\begin{array}{l}\text { Trocar e Combinar aprendizados de práticas e } \\
\text { conceitos por meio de documentos e reuniões } \\
\text { - Combinação (Conhecimento explícito em } \\
\text { conhecimento explícito). }\end{array}$ & $6,3 \%$ & $6,3 \%$ & $6,3 \%$ & $6,7 \%$ \\
\hline $\begin{array}{l}\text { Aprender na prática o conhecimento explícito } \\
\text { por meio do compartilhamento de } \\
\text { experiências, documentos e reuniões }- \\
\text { Internalização (Conhecimento explícito em } \\
\text { conhecimento tácito). }\end{array}$ & Não se aplica. & Não se aplica. & $\begin{array}{l}\text { Não se } \\
\text { aplica. }\end{array}$ & $\begin{array}{l}\text { Não se } \\
\text { aplica. }\end{array}$ \\
\hline
\end{tabular}

Fonte: Elaborado pelos autores.

Após realizar as entrevistas e tratar os dados, identificou-se que a produção de conhecimento nas atividades de ensino ocorre principalmente de forma individualizada, e que todo o material produzido, não tem um processo formal de compartilhamento da experiência e/ou material desenvolvido. Constatou-se também que a principal fonte de busca de conhecimento ocorre por meio da Combinação, por meio de materiais já prontos, porém não há compartilhamento e retorno após o tratamento deste 
conhecimento, tornando-o individualizado e obsoleto. A Socialização também aparece de forma significativa em diversas atividades de organização de ensino, sendo a saída para a solução de diversos problemas na rotina dos docentes. Por fim, a Externalização ocorre de forma mínima e informal, o compartilhamento de qualquer experiência e material não ocorre de forma sistematizada, dificultando o processo de Internalização do conhecimento.

Para que o assunto proposto seja discutido com maior amplitude, propõem-se novos estudos com o mesmo objetivo do presente trabalho, com uma amostra de docentes maior e abrangendo outras instituições federais de educação. Ainda, destaca-se a importância de também analisar, além das atividades de ensino, atividades de pesquisa e extensão.

\section{BIBLIOGRAFIA}

BATEMAN, Thomas S.; Snell, Scott A. Administração: A ética, a onda verde e a responsabilidade social - como lidar com as preocupações da atualidade. Porto Alegre: AMGH, 2012.

DRUCKER, Peter Ferdinand. A administração na próxima sociedade. São Paulo: Nobel, 2002.

FALCONI, Vicente. O verdadeiro poder: práticas de gestão que conduzem a resultados revolucionários. Nova Lima: INDG Tecnologia e Serviços Ltda, 2009.

FLEURY, Maria Tereza Leme; JR., Moacir de Miranda Oliveira. Gestão estratégica do conhecimento: integrando aprendizagem, conhecimento e competências. São Paulo: Atlas, 2008.

GIL, Antonio Carlos. Métodos e técnicas de pesquisa social. São Paulo: Atlas, 2008.

GRAMSCI, Antonio. Os Intelectuais e a Organização da Cultura. A administração na Próxima Sociedade. Rio de Janeiro: Civilização Brasileira, 1982.

INSTITUTO FEDERAL DE SANTA CATARINA - Câmpus Xanxerê, O Câmpus. Disponível

em: $<$ http://xanxere.ifsc.edu.br/index.php?option=com_content $\& v i e w=a r t i c l e \& i d=56 \& I t$ emid=29> . Acesso em 5 de Julho de 2017.

INSTITUTO FEDERAL DE SANTA CATARINA, Institucional - missão, visão e valores. Disponível em: 〈http://www.ifsc.edu.br/menu-institucional/missao >. Acesso 
em 5 de Julho de 2017.

INSTITUTO FEDERAL DE SANTA CATARINA. Colegiados, conselho superior, resoluções - $\quad$ resolução 23/2014. Disponível em: $<$ http://cs.ifsc.edu.br/portal/files/Consup2014/consup resolucao23 2014 atividades\%2 0docentes_ifsc.pdf>. Acesso em 5 de Julho de 2017.

NONAKA, Ikujiro; TAKEUCHI, Hirotaka. Criação de conhecimento na empresa: como as empresas japonesas geram a dinâmica da inovação. Rio de Janeiro: Campus, 1997.

SENGE, Peter M. A Quinta Disciplina: arte e prática da organização que aprende. São Paulo: Best Seller, 1998.

STEWART, Thomas A., Capital Intelectual: a nova vantagem competitiva das empresas. Rio de Janeiro: Elsevier, 1998.

SVEIBY, Karl Erik. A nova riqueza das organizações: gerenciando e avaliando patrimônios de conhecimento. Rio de Janeiro: Campus, 1998.

VASCONCELLOS, Celso dos Santos. Planejamento: projeto de ensino-aprendizagem e projeto político-pedagógico - elementos metodológicos para elaboração e realização. São Paulo: Libertad, 2002. 